\title{
A RELAÇÃO ENTRE AS CONDIÇÕES DE TRABALHO E SAÚDE DOS ESTUDANTES TRABALHADORES
}

\section{Marcia Silva Pereira}

Mestranda do Programa de Pós-graduação em Promoção da Saúde do Centro Universitário de Maringá UNICESUMAR, Maringá (PR), Brasil.

\section{Regiane da Silva Macuch}

Docente no Programa de Pós-graduação em Promoção da Saúde do Centro Universitário de Maringá UNICESUMAR, Maringá (PR); Pesquisadora do ICETI - Instituto Cesumar de Ciência, Tecnologia e Inovação; Brasil.

\section{E-mail: rmacuch@gmail.com}

\section{Flavio Bortolozzi}

Docente no Programa de Pós-graduação em Promoção da Saúde do Centro Universitário de Maringá UNICESUMAR, Maringá (PR); Pesquisadora do ICETI - Instituto Cesumar de Ciência, Tecnologia e Inovação; Brasil.

\section{Sonia Maria Marques Gomes Bertolini}

Docente no Programa de Pós-graduação em Promoção da Saúde do Centro Universitário de Maringá UNICESUMAR, Maringá (PR); Pesquisadora do ICETI - Instituto Cesumar de Ciência, Tecnologia e Inovação; Brasil.

\section{Mateus Dias Antunes}

Mestrando do Programa de Pós-graduação em Promoção da Saúde do Centro Universitário de Maringá - UNICESUMAR, Maringá (PR), Brasil; Bolsista da CAPES.
RESUMO: O objetivo deste estudo foi correlacionar condições de saúde às de trabalho de estudantes universitários trabalhadores a partir de uma revisão de literatura com a finalidade de sugerir ações promotoras de saúde. A pesquisa realizou-se por meio de revisão de literatura e pesquisa de campo, em que discute e analisa a relação entre as condições de trabalho e a saúde dos estudantes trabalhadores. O tempo de estudo escasso, a carga horária de trabalho associada e as horas insuficientes de descanso interferem diretamente no rendimento acadêmico familiar e laboral do estudante, podendo provocar distúrbios físicos, familiares e emocionais. É importante considerar que alguns hábitos podem prejudicar o rendimento dos mesmos como dormir tarde, má alimentação. Refletir sobre a realidade, as dificuldades enfrentadas e os fatores que possam afetar o desempenho do estudante trabalhador para promover sua saúde e qualidade de vida é importante. Foi possível identificar as situações que podem levar esse público à má qualidade de vida $\mathrm{e}$ ao adoecimento, embora muitas vezes, os próprios não percebam tal fato, considerando boas suas condições de saúde. Os resultados desta pesquisa apontam para a necessidade de novos estudos sobre a qualidade de vida dos estudantes universitários e podem trazer grandes contribuições para a proposição de ações promotoras de saúde aos mesmos.

PALAVRAS-CHAVE: Condições de trabalho; Nível de saúde; Promoção da Saúde; Qualidade de vida.

\section{RELATIONSHIP BET WEEN LABOR CONDITIONS AND HEALTH OF WORKING STUDENTS}

\begin{abstract}
Current investigation co-relates health conditions to labor conditions os working university students by a review of the literature for health enhancement activities. Research comprised a review of the literature and field research to analyze the relationships between labor conditions and the health of working students. Short study period, work load and insufficient rest time directly interfere on the academic yield and work of the students, with serious physical, family and emotional disorders. Certain habits, such as sleeping late and bad feeding actually harm school performance. It is highly important to discuss the difficulties to be coped with and the factors that may influence student's performance for health improvement and better life quality. The situations that lead this type of population to a bad life quality and illness may be identified, even though they themselves fail to perceive this fact and think they have good health. Results reveal the need for further studies on the life quality of working students, with significant contributions for better health enhancements.
\end{abstract}

KEY WORDS: Working conditions; Health status; Health promotion; Quality of life. 


\section{INTRODUÇão}

O ingresso nas universidades é um momento importante na vida dos jovens estudantes trabalhadores (GUERREIRO; CASANOVA; POLYDORO, 2010). Porém, para muitos é uma experiência estressante que interfere no próprio rendimento acadêmico e no aspecto psicológico como alteração nas rotinas e nos hábitos alimentares (PEREIRA, 2006).

Com o crescimento do número de universitários e as novas demandas faz-se necessário refletir sobre à qualidade de vida dos mesmos, bem como sobre o que os afeta (SCHLEICH, 2006, JOLY; SANTOS; SISTO, 2005). Deste modo, o interesse por estudos com universitários aumentou haja vista o crescimento do número de pessoas que frequentam a universidade.

Para a promoção da saúde e qualidade de vida do estudante trabalhador, primeiro, faz-se necessário conhecer a realidade vivenciada pelos universitários bem como a qualidade de vida dos mesmos pois há poucos estudos a respeito disso (TEIXEIRA; CASTRO; PICOLO, 2007).

As exigências das organizações, bem como as condições de trabalho oferecidas provocam situações de estresse (MARRAS; VELOSO, 2012). Os sintomas podem ser físicos ou psicológicos. Os sintomas físicos de acordo com Peiffer (2007) podem ser tensões nas mandíbulas, ombro, estômago, peito, dor de cabeça. Também incluem dificuldades respiratórias, inquietação, tiques, boca seca, sudorese, exaustão, diarreia, necessidade de urinar com frequência, problemas para dormir, oscilações nos níveis de açúcar no sangue e outros. Os sintomas psicológicos também são abordados pelo autor como por exemplo, falta de concentração, esquecimento, dificuldade para lembrar de fatos recentes, dificuldade de absorver informações, indecisão, tomada de decisão precipitada, cometimento de erros com mais frequência.

A ansiedade é um conceito psicológico inerente à condição humana (GUERREIRO,2009). É vista como uma reação necessária e natural. Pode ser considerada benéfica se for adequada às circunstâncias e para responder aos diversos estímulos. Caso seja controlada atua como estimulante ou força motivadora, se for em excesso provoca consequências e interferências na vida das pessoas (OLIVEIRA,2011).
Segundo Robbins (2005, p.441) as pessoas trabalham em média de 40 a 50 horas por semana. Mas as experiências e os problemas vividos no restante do tempo podem ter efeitos no trabalho. Um fato que costuma ser menosprezado é que os fatores de estresse são um fenômeno cumulativo. O estresse se intensifica. Cada fator novo e persistente faz crescer o nível de estresse do indivíduo. Assim um determinado fator pode ser de pouca importância quando observado isoladamente, mas pode se tornar "a gota d'água quando somada a um nível de estresse já alto". Para avaliar o nível real de estresse enfrentado por alguém, temos de somar todos os fatores.

Alkimim (2013, p.83) ressalta que a saúde mental do trabalhador na moderna organização do trabalho tem gerado interesse noâmbito mundial, sendooassédio moral um dos maiores fatores de origem do stress profissional que, por sua vez pode evoluir para desencadear diversos tipos de doenças no trabalhador (melancolia, depressão, problemas no sistema nervoso, no aparelho digestivo, no aparelho circulatório, enxaqueca, cefaléias, distúrbios do sono, etc) podendo trazer consequências traumáticas e até mesmo uma desestabilização permanente.

Maximiano (2009) afirma que o "Clima Organizacional" em essência é uma medida de como as pessoas se sentem em relação à empresa e seus administradores, tendo seu conceito evoluído para o conceito de qualidade de vida no trabalho. De acordo com Vecchi (2008, p. 306-307) é importante usar linguagem apropriada, adotar comunicação empática, incentivar o feedback pois um comunicador por meio do feedback pode verificar se uma mensagem foi recebida de modo preciso. Desenvolver um clima de confiança com diálogo honesto e franco. Incentivar a escuta eficaz evitando julgamento de opiniões, oferecer o feedback. A escuta ativa que envolve reafirmar as observações de quem está se comunicando e refletir sobre elas, transmite a mensagem de que o ouvinte está interessado no comunicador como a pessoa e que considera importante o que está sendo falado.

Assim, a partir de um levantamento bibliográfico sobre o tema, nos propusemos a correlacionar condições de saúde e de trabalho de estudantes universitários trabalhadores para, após coleta e análise dos dados, sugerir ações promotoras de saúde. 


\section{METODOLOGIA}

Pesquisa de natureza quanti-qualitativa, exploratória, descritiva e transversal com aplicação de questionário a estudantes universitários trabalhadores do curso de Ciências Contábeis de uma Instituição de Ensino Superior do Noroeste do Paraná.

Para dar conta de responder aos objetivos da pesquisa foi realizada a aplicação de um questionário. $\mathrm{O}$ questionário foi construído com base em outros questionários e continha 20 questões fechadas divididas em 3 blocos, a saber: perfil sociodemográfico, condições de trabalho e condições de saúde.

Os estudantes que participaram do estudo cursavam Ciências Contábeis no período noturno em uma instituição particular de Ensino Superior no Noroeste do Paraná. Do total de 132 estudantes que responderam ao questionário, 12 foram desconsiderados uma vez que não trabalhavam, e atualmente estavam desempregados, assim 120 estudantes foram considerados para as análises.

A coleta de dados ocorreu no mês de agosto de 2016, após aprovação do Comitê de Ética sob o Número do Parecer: 1.627.138 e autorização do local e anuência de participação dos estudantes por meio da assinatura do Termo de Consentimento Livre e Esclarecido - TCLE.

Os dados foram analisados por meio de estatística descritiva realizada por estatístico profissional.

\section{RESULTADOS E DISCUSSÃO}

Para a apresentação dos resultados obtidos na pesquisa de campo, tais resultados foram organizados em tabelas de acordo com os blocos do questionário para facilitar a discussão.

\subsection{PERFIL SOCIODEMOGRÁFICO DOS ESTUDANTES- TRABALHADORES}

A maioria dos estudantes que participaram do estudo, (59\%) possui de 20 a 25 anos de idade, enquanto 14\% têm menos de 20 anos e apenas 12\% possuem 30 anos ou mais. $55 \%$ dos estudantes que participaram da pesquisa eram do sexo masculino e $45 \%$ feminino.
Quanto ao estado civil, 78\% disseram ser solteiros e 18\% casados ou união de fato.

Apenas um décimo dos respondentes afirmou ter cursado outra graduação, sendo que $32 \%$ não responderam à pergunta.

Quase um terço dos estudantes está há um ano ou menos no emprego atual, assim como quase um terço trabalha de 1 a 3 anos. O rendimento mensal de $29 \%$ dos estudantes esteve entre $R \$ 1000,00$ e $\mathbf{R} \$ 1500,00$ e $23 \%$ recebe mais de $\mathrm{R} \$ 2000,00$ mensalmente.

Quando questionados sobre a cidade de residência, 59\% dos estudantes disseram ser de Maringá enquanto $41 \%$ são de outras cidades, como Sarandi e Marialva. Ainda, observou-se que apenas $11 \%$ dos estudantes responderam que não estão felizes na faculdade ou no curso que escolheram para exercer como profissão.

Tabela 1. Frequências absolutas e relativas das características sociodemográficas dos estudantes participantes da pesquisa

(continua)

\begin{tabular}{lll}
\hline Fatores & Frequência & $\%$ \\
\hline
\end{tabular}

Participantes (divididos por série escolar)

$\begin{array}{lll}1^{\circ} \text { ano } & 16 & 13 \% \\ 2^{\circ} \text { ano } & 32 & 27 \% \\ 3^{\circ} \text { ano } & 34 & 28 \% \\ 4^{\circ} \text { ano } & 38 & 32 \% \\ \text { Idade } & & \\ <20 \text { anos } & 17 & 14 \% \\ 20 \mid-25 \text { anos } & 71 & 59 \% \\ 25 \mid-30 \text { anos } & 17 & 14 \% \\ \geq 30 & 15 & 12 \%\end{array}$

Sexo

$\begin{array}{lll}\text { Feminino } & 54 & 45 \% \\ \text { Masculino } & 66 & 55 \%\end{array}$

Estado civil

Casado

Solteiro

União de fato $6 \%$

Não respondeu

7

$4 \%$ 
(conclusão) os resultados obtidos quanto às condições de trabalho

\begin{tabular}{lcc}
\hline Fatores & Frequência & $\%$ \\
\hline Não & 70 & $58 \%$ \\
Sim & 12 & $10 \%$ \\
Não respondeu & 38 & $32 \%$
\end{tabular}

Tempo no emprego atual

$\begin{array}{lcc}\leq 1 \text { ano } & 39 & 32 \% \\ 1-\mid 3 \text { anos } & 39 & 32 \% \\ 3-\mid 5 \text { anos } & 26 & 22 \% \\ >5 \text { anos } & 14 & 12 \% \\ \text { Não respondeu } & 2 & 2 \%\end{array}$

Rendimento mensal

$\begin{array}{lcc}\text { Até } \mathrm{R} \$ 500 & 2 & 2 \% \\ \text { Entre } \mathrm{R} \$ 500 \text { e R\$1000 } & 25 & 21 \% \\ \text { Entre } \mathrm{R} \$ 1000 \text { e R\$ } 1500 & 35 & 29 \% \\ \text { Entre R\$ } 1500 \text { e R \$2000 } & 27 & 22 \% \\ \text { Acima de R\$2000 } & 28 & 23 \% \\ \text { Não respondeu } & 3 & 3 \%\end{array}$

Cidade de Residência

$\begin{array}{lll}\text { Maringá } & 71 & 59 \% \\ \text { Outras } & 49 & 41 \%\end{array}$

Feliz com a faculdade/curso que escolheu destes estudantes-trabalhadores pesquisados.

\subsection{CONDIÇÕES DE TRABALHO}

A evolução do sistema produtivo introduzida pela revolução tecnológica e de globalização de mercados, alterou profundamente a organização do trabalho refletindo na supressão de categorias, cargos como, por exemplo, eliminação de gerentes intermediários, organização descentralizada, com preponderância do trabalho em equipe que por sua vez é responsável pela manutenção e qualidade da produção, além da delegação de tomada de decisões. Nesse período pós-industrial e neoliberal há uma tendência de transferir os riscos, a ausência de resultados ou a evolução de tarefas e das técnicas para os assalariados (ALKIMIN, 2013).

Tabela 2. Frequências absolutas e relativas das condições de trabalho dos estudantes participantes da pesquisa

\begin{tabular}{|c|c|c|}
\hline Fatores & Frequência & $\%$ \\
\hline \multicolumn{3}{|l|}{$\begin{array}{l}\text { Gosta da área em que trabalha } \\
\text { atualmente }\end{array}$} \\
\hline Não & 12 & $10 \%$ \\
\hline Não se aplica & 5 & $4 \%$ \\
\hline Sim & 102 & $85 \%$ \\
\hline Não respondeu & 1 & $1 \%$ \\
\hline \multicolumn{3}{|l|}{$\begin{array}{l}\text { Considera o salário adequado as } \\
\text { funções que desempenha }\end{array}$} \\
\hline Não & 57 & $48 \%$ \\
\hline Sim & 62 & $52 \%$ \\
\hline Não respondeu & 1 & $1 \%$ \\
\hline \multicolumn{3}{|l|}{$\begin{array}{l}\text { Modo como a chefia toma } \\
\text { decisóes }\end{array}$} \\
\hline $\begin{array}{l}\text { Decide sem consultar os(as) } \\
\text { subordinados(as) }\end{array}$ & 26 & $22 \%$ \\
\hline $\begin{array}{l}\text { Somente algumas decisões sem } \\
\text { significado são transferidas para } \\
\text { outras pessoas }\end{array}$ & 12 & $10 \%$ \\
\hline $\begin{array}{l}\text { Ele(a) somente decide após } \\
\text { consultar os(as) subordinados(as) }\end{array}$ & 17 & $14 \%$ \\
\hline $\begin{array}{l}\text { A decisão é tomada conjuntamente } \\
\text { pelo(a) chefe e subordinados (as) }\end{array}$ & 48 & $40 \%$ \\
\hline
\end{tabular}

O trabalho tem significado relevante na vida do indivíduo, o que leva o mesmo a ter sentimento de pertença à classe trabalhadora, reforçando sua identidade (RIBEIRO, et. al, 2011). Sobre a importância que o trabalho tem na vida das pessoas, AlkimIn (2013, p.84) enfatiza que o homem busca no trabalho não apenas a fonte de sobrevivência, mas a satisfação para si e sua família, pois no trabalho destaca o homem no seio da família e da sociedade e, se o trabaalho não cumpre essa finalidade, gera insatisfação no mesmo, isolamento do trabalhador, além de alterações comportamentais, podendo desestabilizar o convívio familiar e social do trabalhador.

Neste sentido, no tópico a seguir apresentam-se 
(continua)

\begin{tabular}{|c|c|c|c|c|c|}
\hline Fatores & Frequência & $\%$ & Fatores & Frequência & $\%$ \\
\hline \multirow{2}{*}{$\begin{array}{l}\text { Chefe dá liberdade para } \\
\text { decidirmos por nós, desde } \\
\text { que respeitemos as limitações } \\
\text { existentes }\end{array}$} & & & Não respondeu & 5 & $4 \%$ \\
\hline & 14 & $12 \%$ & $\begin{array}{l}\text { Há pressões para que trabalhe } \\
\text { mesmo com atestado médico }\end{array}$ & & \\
\hline Não respondeu & 3 & $3 \%$ & Nunca & 95 & $79 \%$ \\
\hline Estilo do(a) chefe & & & Raramente & 8 & $7 \%$ \\
\hline \multirow{2}{*}{$\begin{array}{l}\text { Atribui muita importância para } \\
\text { a produção e demonstra um } \\
\text { interesse mínimo pelo indivíduo }\end{array}$} & \multirow[b]{2}{*}{18} & \multirow[b]{2}{*}{$15 \%$} & Frequente & 4 & $3 \%$ \\
\hline & & & Às vezes & 5 & $4 \%$ \\
\hline \multirow{2}{*}{$\begin{array}{l}\text { Atribui muita importância para o } \\
\text { indivíduo e um interesse mínimo } \\
\text { pela produção }\end{array}$} & & & Sempre & 5 & $4 \%$ \\
\hline & 1 & $1 \%$ & Não respondeu & 3 & $3 \%$ \\
\hline Tem um interesse mínimo pelo & \multirow[t]{2}{*}{7} & \multirow{2}{*}{$6 \%$} & $\begin{array}{l}\text { Fica exposto a uma carga de } \\
\text { trabalho excessiva }\end{array}$ & & \\
\hline tradallador e pera produçao & & & Nunca & 59 & $49 \%$ \\
\hline $\begin{array}{l}\text { Tem um interesse máximo pelo } \\
\text { trabalhador e pela produção }\end{array}$ & 54 & $45 \%$ & Raramente & 22 & $18 \%$ \\
\hline \multirow{2}{*}{$\begin{array}{l}\text { Demonstra um interesse regular } \\
\text { pelo trabalhador e pela produção }\end{array}$} & \multirow{2}{*}{38} & \multirow{2}{*}{$32 \%$} & Frequente & 13 & $11 \%$ \\
\hline & & & Às vezes & 17 & $14 \%$ \\
\hline Não respondeu & 2 & $2 \%$ & Sempre & 7 & $6 \%$ \\
\hline \multicolumn{3}{|l|}{$\begin{array}{l}\text { Há pressão dos superiores para } \\
\text { cumprir metas }\end{array}$} & Não respondeu & 2 & $2 \%$ \\
\hline Nunca & 17 & $14 \%$ & \multirow{2}{*}{$\begin{array}{l}\text { Alguma vez foi humilhado/ } \\
\text { ridicularizado em relação ao } \\
\text { trabalho }\end{array}$} & & \\
\hline Raramente & 26 & $22 \%$ & & & \\
\hline Frequente & 19 & $16 \%$ & Nunca & 96 & $80 \%$ \\
\hline Às vezes & 36 & $30 \%$ & Raramente & 11 & $9 \%$ \\
\hline Sempre & 20 & $17 \%$ & Às vezes & 9 & $8 \%$ \\
\hline Não respondeu & 2 & $2 \%$ & Sempre & 2 & $2 \%$ \\
\hline \multirow{2}{*}{$\begin{array}{l}\text { É comum fazer horas extras no } \\
\text { local de trabalho }\end{array}$} & & & Não respondeu & 2 & $2 \%$ \\
\hline & 31 & $26 \%$ & $\begin{array}{l}\text { Situações pelas quais passa em } \\
\text { relação ao superior * }\end{array}$ & & \\
\hline Raramente & 33 & $28 \%$ & $\begin{array}{l}\text { Não lhe cumprimenta e não fala } \\
\text { com você }\end{array}$ & 3 & $2 \%$ \\
\hline Frequente & 5 & $4 \%$ & \multirow{2}{*}{$\begin{array}{l}\text { Pede trabalhos urgentes sem } \\
\text { nenhuma necessidade }\end{array}$} & \multirow{2}{*}{16} & \multirow{2}{*}{$13 \%$} \\
\hline Às vezes & 31 & $26 \%$ & & & \\
\hline Sempre & 16 & $13 \%$ & \multirow[t]{2}{*}{$\begin{array}{l}\text { Dá instruções confusas e } \\
\text { imprecisas }\end{array}$} & \multirow[t]{2}{*}{20} & \multirow[t]{2}{*}{$17 \%$} \\
\hline Não respondeu & 4 & $3 \%$ & & & \\
\hline $\begin{array}{l}\text { Se sente vigiado enquanto } \\
\text { trabalha }\end{array}$ & & & $\begin{array}{l}\text { Ignora sua presença na frente } \\
\text { dos outros }\end{array}$ & 5 & $4 \%$ \\
\hline Nunca & 33 & $28 \%$ & Fala mal de você em público & 2 & $2 \%$ \\
\hline Raramente & 34 & $28 \%$ & $\begin{array}{l}\text { Manda você executar tarefas sem } \\
\text { interesse }\end{array}$ & 11 & $9 \%$ \\
\hline Frequente & 18 & $15 \%$ & Faz circular maldades e calúnias & 3 & $2 \%$ \\
\hline Às vezes & 20 & $17 \%$ & sobre você & 3 & $2 \%$ \\
\hline Sempre & 10 & $8 \%$ & Nenhuma das anteriores & 8 & $7 \%$ \\
\hline
\end{tabular}


(conclusão) demonstra um interesse regular pelo trabalhador e pela

\begin{tabular}{lcc}
\hline Fatores & Frequência & $\%$ \\
\hline$\quad$ Não respondeu & 72 & $60 \%$ \\
$\begin{array}{l}\text { Encontra muitas vezes nas } \\
\text { suas atividades as seguintes } \\
\text { dificuldades * }\end{array}$ & & \\
$\quad \begin{array}{l}\text { Objetivos pouco claros } \\
\text { Carga de trabalho excessiva }\end{array}$ & 11 & $9 \%$ \\
$\quad \begin{array}{l}\text { Utilização insuficiente de } \\
\text { métodos de trabalho mais } \\
\text { modernos } \\
\quad \text { Mudanças frequentes da } \\
\text { organização de trabalho }\end{array}$ & 21 & $17 \%$ \\
$\quad \begin{array}{l}\text { Falta de pessoal } \\
\text { Competição grande entre as }\end{array}$ & 18 & $15 \%$ \\
pessoas & 31 & $26 \%$ \\
$\quad$ Horários não respeitados & 9 & $8 \%$ \\
$\quad$ Nenhuma das anteriores & 14 & $12 \%$ \\
$\quad$ Não respondeu & 5 & $4 \%$ \\
\hline
\end{tabular}

Nota: * A questão admite mais de uma resposta.

Fonte: Dados da pesquisa

Conforme dados da Tabela 2, $85 \%$ dos respondentes da pesquisa disseram gostar da área onde estão trabalhando atualmente. Apesar de sentirem satisfeitos onde atuam 48\% não consideram que o que recebem atualmente é adequado para as funções que desempenham. Na medida em que o ocupante de um cargo conhece seu valor em relação aos demais cargos da organização em relação à situação do mercado pode-se remunerar com justeza e equidade (CHIAVENATO, 2009).

De acordo com $40 \%$ dos estudantes que responderam o questionário, as tomadas de decisões são em conjunto pelo chefe e subordinados e $12 \%$ disseram que o chefe dá liberdade do empregado tomar decisões, porém, respeitando as limitações existentes. Na administração participativa as decisões são compartilhadas (BONOME, 2009, P.73). O envolvimento dos funcionários é uma ferramenta que ajuda o desenvolvimento empresarial visando motivação, satisfação e a valorização dos colaboradores (CHIAVENATO, 2006, p. 221)

Em relação ao estilo do (da) chefe, as opções mais frequentes foram que ele (a) tem um interesse máximo pelo trabalhador e pela produção ou produção, correspondendo a $45 \%$ e $32 \%$ das respostas, respectivamente. Não é possível pensar em meio ambiente sem pensar na sua relação com o ser humano (BOCK, 2011, p.109). A gestão da diversidade é um processo por meio do qual o gestor torna-se sensível às necessidades e diferenças dos outros (ROBINS, 2010,p.53). Conforme Melo (2010) os líderes mudam as pessoas que por sua vez mudam as organizações.

Observa-se que respectivamente $30 \%$ e $17 \%$ dos estudantes-trabalhadores, responderam que às vezes ou sempre há pressão dos superiores para cumprir metas. As políticas de metas das empresas geralmente reforçam a ideia que o trabalhador tem que ser forte, produzir melhor que o concorrente, atender todas as demandas e canalizar a energia individualmente. (BARRETO, 2003). Guedes (2005, p. 161) afirma que raramente razões econômicas são capazes de persuadir organizações para implementar um programa de combate ao terror psicológico. Alckimim (2013, p. 85) ainda reforça que se no ambiente de trabalho houver pressão ou perseguição psicológica, não haverá condições para o trabalhador exercitar sua potencialidade e produzir em quantidade e com qualidade, sem contar com a queda de produtividade em razão dos constantes afastamentos por motivo de saúde ou até mesmo por motivo de acidente de trabalho.

A maioria dos participantes ( $56 \%$ no total) nunca ou raramente se sentem vigiados enquanto trabalham. $\mathrm{O}$ empregador pode dentro dos limites estabelecidos no ordenamento jurídico, verificar se os empregados estão respeitando as exigências e diretrizes estabelecidas para o desempenho das atividades laborativas (GARCIA, 2007).

Apenas $11 \%$ apontaram que frequentemente, às vezes ou sempre há pressões para que trabalhe mesmo com atestado médico. $\mathrm{O}$ trabalhador geralmente teme perder o emprego, entrega-se à produção, silenciase na dor e trabalha doente, pois nessa condição não encontrará novo emprego (BARRETO, 2003).

Ainda, quase metade dos que responderam disseram que nunca ficaram expostos a uma carga de trabalho excessiva e $80 \%$ nunca foram humilhados ou ridicularizados em relação ao trabalho. Atitudes de perseguição, indiferença, discriminação normalmente de forma velada deterioram o ambiente laboral e pode 
resultar em enfermidades graves como a depressão. (GARCIA, 2014)

Um total de $54 \%$ dos estudantes disseram que raramente ou nunca fazem horas extras no local de trabalho, enquanto 26\% apontaram que tal situação ocorre às vezes. Aspectos biológicos, sociais, econômicos e humanos fundamentam a limitação da duração da jornada laboral. Sob o aspecto biológico, jornadas excessivas provocam fadiga física e psíquica aumentando a incidência de doenças ocupacionais. A jornada excessiva afeta o social de quem desempenha o labor haja vista que afasta o mesmo do convívio com seus pares. No que diz respeito ao econômico, quando aumenta a jornada aumenta a produção. Com a limitação da jornada excessiva, haverá diminuição do desemprego e criação de novos postos de trabalho (MARTINS, 2009)

Em relação às situações pelas quais 0 estudante passa em relação ao superior, as opções mais frequentemente citadas foram que o (a) chefe dá instruções confusas e imprecisas e/ou pede trabalhos urgentes sem nenhuma necessidade, apontadas por $17 \%$ e $13 \%$ dos estudantes respectivamente. Entretanto, $60 \%$ dos participantes da pesquisa não responderam à questão. A comunicação eficaz e aberta é essencial para as organizações (VECHHI, 2008, p.291). Barreiras pessoais, físicas ou semânticas podem ser obstáculos à comunicação nas organizações (CHIAVENATO, 2009).

Quanto as dificuldades que os trabalhadores encontram nas suas atividades, $37 \%$ não responderam à pergunta. As dificuldades mais citadas foram a falta de pessoal (26\%), utilização insuficiente de métodos de trabalho mais modernos (18\%) e/ou carga de trabalho excessiva (17\%), como apresentado na Tabela 2.

O excesso de burocracia, responsabilidades, carga horária excessiva, insatisfação pessoal, mudança de cargo e falta de apoio na execução das tarefas são entre outros fatores que favorecem o estresse no ambiente de trabalho (FIDELIS e BANOV, 2007). A qualidade de vida de quem desempenha o labor é comprometida.

Para além da influência das barreiras a comunicação pode sofrer três males: omissão, distorção, sobrecarga (CHIAVENATO, 2009). As barreiras pessoais são interferências que decorrem das limitações, emoções e valores humanos de cada pessoa. Já as físicas são as interferências que ocorrem no ambiente em que acontece o processo de comunicação. Já as semânticas são as limitações ou distorções decorrentes dos símbolos através dos quais a comunicação é feita. A comunicação é clara e eficaz quando propõe objetivos claros, definidos (PRIOTTO, 2013). As ideias devem ser selecionadas, esquematizadas, planejadas para serem transmitidas (VANETTI, 2015).

\subsection{CONDIÇÕES DE SAÚDE DOS ESTUDANTES}

$\mathrm{Na}$ tabela 3 apresentam-se os resultados relativamente às condições de saúde dos estudantestrabalhadores participantes do estudo.

Tabela 3. Frequências absolutas e relativas das condições de saúde dos estudantes participantes da pesquisa

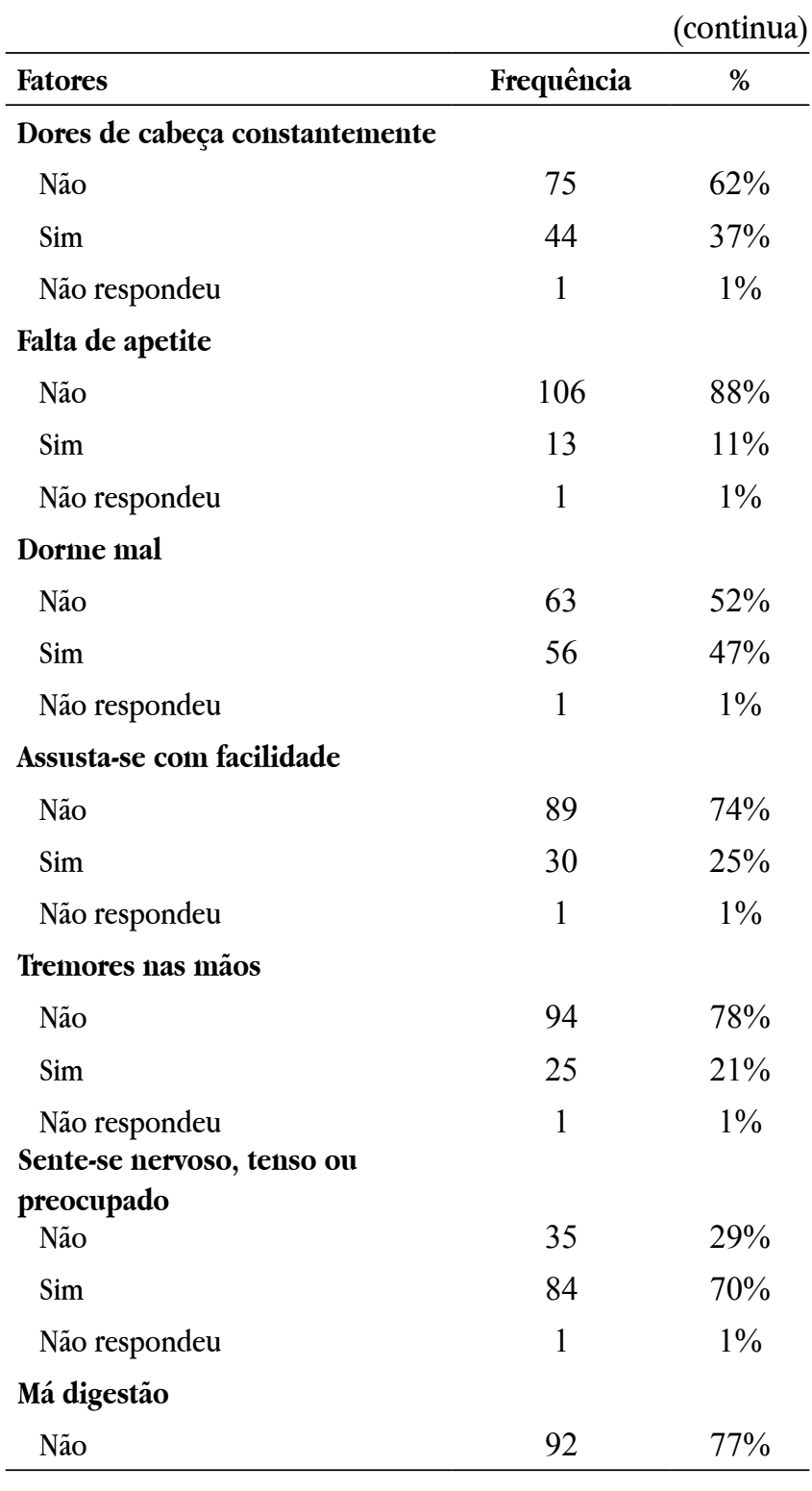


(continua)

\begin{tabular}{l}
\hline Fatores \\
\hline Sim \\
Não respondeu \\
Dificuldade de pensa \\
clareza \\
Não \\
Sim \\
Não respondeu \\
Tem-se sentido triste \\
ultimamente \\
Não \\
Sim
\end{tabular}

Não respondeu

Chorado mais que de costume

$$
\text { Não }
$$

Sim

Não respondeu

Dificuldade para realizar com satisfação suas atividades

Sim

Não respondeu

Dificuldade para tomar decisões

\section{Não}

Sim

Não respondeu

Dificuldade no serviço

$$
\text { Não }
$$$$
\text { Sim }
$$

Não respondeu

É incapaz de desempenhar um papel útil na sua vida

Não

$$
\text { Sim }
$$

Não respondeu

Tem perdido o interesse pelas

coisas

Não

$$
\text { Sim }
$$

Não respondeu

Sente-se uma pessoa inútil, sem préstimo

$$
\text { Não }
$$

Sim

Não respondeu

Sente-se cansado o tempo todo

\begin{tabular}{lll} 
Não & 57 & $48 \%$ \\
Sim & 62 & $52 \%$ \\
\hline
\end{tabular}

(conclusão)

\begin{tabular}{lcc}
\hline Fatores & Frequência & $\%$ \\
\hline $\begin{array}{l}\text { Não respondeu } \\
\text { Sensaçóes desagradáveis no } \\
\text { estômago }\end{array}$ & 1 & $1 \%$ \\
$\quad$ Não & & \\
Sim & 77 & $64 \%$ \\
$\quad$ Não respondeu & 42 & $35 \%$ \\
Se cansa com facilidade & 1 & $1 \%$ \\
$\quad$ Não & & \\
Sim & 67 & $56 \%$ \\
$\quad$ Não respondeu & 52 & $43 \%$ \\
Como considera sua condição & 1 & $1 \%$ \\
de saúde & & \\
Ruim & 5 & $4 \%$ \\
Regular & 33 & $28 \%$ \\
Boa & 57 & $48 \%$ \\
Excelente & 20 & $17 \%$ \\
Não respondeu & 5 & $4 \%$ \\
\hline Fonte: Dados da pesquisa & & \\
& &
\end{tabular}

Quase metade dos participantes da pesquisa (47\%) respondeu que dorme mal. Diversos autores abordam como o sono pode afetar a qualidade de vida. A redução do tempo de sono e sua privação são consideradas fatores de risco para a população (MELLO; SANTOS, PIRES, 2008). Na população brasileira a estimativa de alterações do sono é aproximadamente de dez a vinte milhões de pessoas (MÜLLER; GUIMARÃES, 2007). A população dorme em média 90 minutos a menos do que dormia no início do século XX (SUCHECKI; D’ALMEIDA, 2008, p.78).

Estudantes apresentam-se como grupo de risco para o desenvolvimento de distúrbios relacionados ao sono, por exemplo, sonolência diurna excessiva, que pode interferir na sua saúde e rendimento acadêmico (PEREIRA, 2011). Todos os estágios do sono caminham para a satisfação das necessidades metabólicas, sendo necessário para que o corpo funcione normalmente (SADOCK, B.; SADOCK, V., 2007).

A privação do sono, bem como a sonolência excessiva observada na sociedade são questões que preocupam a saúde pública, é possível associar a redução da qualidade de vida, produtividade, bem-estar, aumento de acidentes (MELLO; SANTOS; PIRES, 2008). As alterações no sono podem causar modificações na qualidade de vida, disfunção autonômica e redução 
da vigilância, influencia negativamente o rendimento profissional ou acadêmico, eleva o número de transtornos psiquiátricos, culminando na diminuição da expectativa de vida e precocidade no envelhecimento (CARDOSO et al, 2009).

Diversos fatores contribuem para a redução da quantidade de sono entre estudantes universitários, dentre os quais estão alimentação inadequada, sedentarismo, trabalho, longo período diante de computadores, horários (COELHO et al, 2010; PEREIRA et al, 2011). As estratégias para promoção da qualidade de sono devem ser vistas como prioridade.

Foi observado que $37 \%$ dos estudantes relataram sentir dores de cabeça constantemente e 11\% disseram ter falta de apetite. A maioria dos estudantes (70\%) relatou que se sente nervoso, tenso ou preocupado, ao passo que $22 \%$ e $26 \%$ disseram ter má digestão e dificuldade para pensar com clareza, respectivamente. Um pouco mais de $20 \%$ tem tremores nas mãos.

Conforme Mello, Santos, Silva(2008) cansaço, fadiga e indisposição física incompatíveis com a situação de uma pessoa podem ser sintomas de doenças endócrinas, imunes, infecciosas, hematológicas, oncológicas ou dos sistemas nervoso, central e periférico. Nas doenças mentais há às vezes contraditoriamente ao mesmo tempo pensamento e humor agitados e queixa de fadiga.

Pouco mais de um terço dos indivíduos apontou estar sentido tristeza ultimamente e 16\% tem chorado mais do que de costume. Pessoas deprimidas choram frequentemente, a baixa autoestima é um atributo característico da depressão (BECK; ALFORD 2011, p.28).

Em relação às dificuldades para realizar com satisfação sua atividade, tomar decisões e no serviço, os estudantes responderam respectivamente $31 \%, 34 \%$ e $17 \%$ para tais dificuldades. Vacilar entre alternativas e mudar de decisões são características de depressão. Decisões rotineiras que devem ser tomadas no desempenho de seus papéis ocupacionais ou domésticos tornam -se um grande problema para os deprimidos, a perda da satisfação pode começar com algumas atividades e, à medida que a depressão evolui se difunde para praticamente tudo que o paciente faz (BECK; ALFOR, 2011, p. 32).

Por fim, quando questionados em relação a sua condição de saúde, $48 \%$ dos estudantes a consideram boa e $17 \%$ excelente, sendo que apenas $4 \%$ apontaram que considera sua condição de saúde ruim. Na maioria das vezes as pessoas trabalham doentes por medo de serem demitidas, e principalmente, autoescondem de si mesmas determinados sintomas. Conforme Barreto (2013), os médicos que atendem em ambulatórios das empresas incorrem frequentemente em problemas éticos omitindo os riscos existentes à saúde, não fornecem os resultados dos exames realizados ou cópia do prontuário quando solicitados, não notificam as doenças ou acidentes de trabalho, ignoram, ridicularizam atestados dos colegas.

\section{CONCLUSÕES}

Por meio do estudo realizado foi possível identificar as situações que podem levar estudantestrabalhadores à má qualidade de vida e ao adoecimento, embora muitas vezes, os próprios não percebam tal fato, considerando terem boas suas condições de saúde.

Quando questionados sobre o estado de saúde, há um número considerável de estudantes que dorme mal, apresentam-se nervosos e preocupados. Tais sintomas comprometem a saúde e qualidade de vida dos mesmos. É fundamental preocupar-se com a saúde e qualidade de vida desse grupo de estudantes, haja vista que os sintomas apresentados podem comprometer a saúde e qualidade de vida dos mesmos.

Pesquisar sobre a saúde dos estudantestrabalhadores contribui para que medidas de promoção da saúde possam ser adotadas por escolas, universidades e empresas. A universidade promotora da saúde pode ser uma grande referência para práticas, políticas e atitudes de educação em saúde atuando como espaço estratégico para promoção da mesma.

As políticas públicas vigentes no Brasil possibilitam acesso de um público universitário heterogêneo e devido à necessidade encontrada pelos estudantes-trabalhadores de conciliar estudo e trabalho, faz-se necessário preocupar-se com a saúde e qualidade de vida dessa parcela significativa da população que na busca por melhores condições de vida, após jornada extenuante de trabalho frequentam a universidade e necessitam que estratégias promotoras da saúde sejam adotadas tanto pelas instituições educacionais que os recebem como pelo contexto laboral ao qual estão inseridos. 


\section{REFERÊNCIAS}

ALKIMIN, M.A. Assédio moral na relação de trabalho. Curitiba: Juruá, 2013.

BARRETO, M.M.S. Violência, saúde, trabalho: uma jornada de humilhações. São Paulo: EDUC da PUCSP, 2003.

BECK, A.T.; ALFORD, B. A. Depessão: causas e tratamento. Tradução Daniel Bueno. Porto Alegre: Artmed, 2011.

BOCK, A.M.B. Psicologia fácil. São Paulo, Saraiva, 2011.

BONOME, J. B. V. Teoria geral da administração. Curitiba IESDE Brasil S.A., 2009.

CARDOSO, L.R.; BZUNECK, J.A. Motivação no ensino superior: metas de realização e estratégias de aprendizagem. Educacional, v. 8, n. 2, p. 145-155, 2004. Disponível em: <http://www.scielo.br/pdf/pee/v8n2/ v8n2a03.pdf $>$. Acesso em: 10 ago. 2016.

CAVESTRO, J.M; ROCHA, F.L. Prevalência da depressão entre estudantes universitários. J Bras Psiquiatr, Minas Gerais, v.55, n 4, p.264-7, set. 2006.

CHIAVENATO, I. Recursos humanos, o capital humano das organizações. São Paulo: Atlas, 2009.

CHIAVENATO, I. Administração de recursos humanos: fundamentos básicos. São Paulo: Atlas, 2006.

COELHO, A.T.; LORENZINI, L.M.; SUDA, E.; ROSSINI, S; REIMÃO, R. Qualidade do sono, depressão e ansiedade em universitários nos últimos semestres dos cursos da área da saúde. Neurobiologia, São Paulo, v.73, n.1, p.359, jan./mar.2010.

FREITAS, M.E. Assédio moral e assédio sexual: faces do poder perverso nas organizações. Rev Administração de Empresas, São Paulo, v. 41, n.2, p. 8-18, 2001.

FIDELIS, G.J.; BANOV, M.R. Gestão de Recursos humanos e estratégica. São Paulo: Érica, 2007.

GARCIA, G.F.B. Curso de direito do trabalho. São Paulo: Método, 2007.

GARCIA, G.F.B. Curso de direito do trabalho. 8. ed. rev. atual. ampl. Rio de Janeiro: Forense, 2014.

GUEDES, M.N. Terror psicológico no trabalho. São
Paulo: LRT, 2005.

GUERREIRO CASANOVA, D.; POLYDORO, S. Integração ao Ensino Superior: relação ao longo do primeiro ano de graduação. Psicologia, ensino e formação, v. 1, n. 2, Brasília, 2010.

JOLY, M.C.R.A; SANTOS, A.A.A; SISTO, F.F. Questóes do cotidiano universitário: São Paulo: Casa do Psicólogo, 2005.

MARTINS, S.P. Direito Processual do Trabalho. 29. ed. São Paulo: Atlas, 2009.

MARRAS, J.P.; VELOSO, H.M. Estresse ocupacional. Rio de Janeiro: Elsevier, 2012.

MELLO, T. M.; SANTOS, R. H. E.; PIRES, L. N. P. Sonolência e acidentes. In: TUFIK, S. et al. Medicina e biologia do sono. Barueri: Manole, 2008, p. $416-420$.

MULLER, M.R.; GUIMARÃES, S.S. Impacto dos transtornos do sono sobre o funcionamento Diário e a qualidade de vida. Estud. Psicol., Campinas, v. 24, n.4, p. 519-528. out./dec. 2007.

OLIVEIRA, J.AC. Qualidade de vida e desempenho acadêmico de graduandos, 2006. 2011. (Tese de Doutorado em Educação) - Universidade Estadual de Campinas, Campinas, SP.

PEIFFER, V. Estresse? livre-se dele! São Paulo: Butterfly Editora, 2007.

PEREIRA, A.L.; BACHION, M.M. Atualidades em revisão sistemática de literatura, critérios de força e grau de recomendação de evidência. Rev Gaucha Enferm, Porto Alegre, v. 27, n. 4, p. 491-498, dez. 2006.

PEREIRA, E.F; BERNARDO, M.P.S. LB; ALMEIDA,V; LOUZADA, F.M. Sono, trabalho e estudo: duração do sono em estudantes trabalhadores e não trabalhadores. Cad Saúde Pública, Rio de Janeiro, v.27, n.5, p.975-984, mai 2011.

PRIOTTO, E.P. Dinâmicas de grupo para adolescentes. Petrópolis: Vozes, 2013.

RIBEIRO, A.C.A et al; Resiliência no trabalho contemporâneo: promoção e/ou desgaste da saúde mental. Psicol Estud, Maringá v. 16, n 4, p. 623-633, 2011. 
RIBEIRO, M. A. As formas da estruturação da carreira na contemporaneidade: interfaces e articulações teóricotécnicas entre a psicologia organizacionalidem e do trabalho e a orientação profissional. In: ZANELLI et al. (Org.). Processos psicossociais nas organizações e no trabalho. São Paulo: Casa do Psicólogo, 2011, p. 305325.

ROBBINS, S.P. Comportamento organizacional. Tradução técnica Reynaldo Marcondes. 11. ed. São Paulo: Pearson Prentice Hall, 2005.

ROBBINS, S.P. Fundamentos do comportamento organizacional. São Paulo: Prentice Hall, 2010.

SADOCK, B.J.; SADOCK, V.A. Compêndio de psquiatria. Porto Alegre: Artmed, 2007.

SCHLEICH, A. L. R. Integração na educação superior e satisfação acadêmica de estudantes ingressantes e concluintes. 2006. 182f. Dissertação (Mestrado em Educação) - Universidade Estadual de Campinas, Campinas, 2006. Disponível em: < http://www.bdae.org. br>. Acesso em: 12 jan. 2017.

SUCHECKI, D.; D'ALMEIDA, V. Privação de sono. In: TUFIK, S. et al. Medicina e biologia do sono. Barueri: Manole, 2008. p. 71 - 87.

TEIXEIRA, M.A.P.;CASTRO, G.D.; PICOLLO, L. R. Adaptação à universidade em estudantes universitários: um estudo correlacional. Integração em Psicologia. v. 11,n. 2, p. 211-220, 2007. Disponível em: < http:/bases. bireme.br>. Acesso em: 12 jan. 2017.

VANETTI, L. Comunicação eficaz: sua importância nas organizações. [s.l.; s.n.], 2015.

VARGAS, M.L.F. Ensino Superior, assistência estudantil e mercado de trabalho, um estudo com egressos da UFMG. [s.l.; s.n.], 2010.

VECCHIO, R.P. Comportamento organizacional: conceitos básicos. São Paulo, CENGAGE Learning, 2008.

Recebido em: 25 setembro de 2016

Aceito em: 14 de fevereiro de 2017 